\title{
The effect of Arctic sea-ice extent on the absorbed (net) solar flux at the surface, based on ISCCP-D2 cloud data for 1983-2007
}

\author{
C. Matsoukas ${ }^{1}$, N. Hatzianastassiou ${ }^{2}$, A. Fotiadi ${ }^{2}$, K. G. Pavlakis ${ }^{3}$, and I. Vardavas ${ }^{4}$ \\ ${ }^{1}$ Department of Environment, University of the Aegean, Greece \\ ${ }^{2}$ Laboratory of Meteorology, Department of Physics, University of Ioannina, Greece \\ ${ }^{3}$ Department of General Applied Science, Technological Educational Institute of Crete, Greece \\ ${ }^{4}$ Department of Physics, University of Crete, Greece
}

Received: 4 May 2009 - Published in Atmos. Chem. Phys. Discuss.: 6 October 2009

Revised: 21 December 2009 - Accepted: 8 January 2010 - Published: 26 January 2010

\begin{abstract}
We estimate the effect of the Arctic sea ice on the absorbed (net) solar flux using a radiative transfer model. Ice and cloud input data to the model come from satellite observations, processed by the International Satellite Cloud Climatology Project (ISCCP) and span the period July 1983June 2007. The sea-ice effect on the solar radiation fluctuates seasonally with the solar flux and decreases interannually in synchronisation with the decreasing sea-ice extent. A disappearance of the Arctic ice cap during the sunlit period of the year would radically reduce the local albedo and cause an annually averaged $19.7 \mathrm{Wm}^{-2}$ increase in absorbed solar flux at the Arctic Ocean surface, or equivalently an annually averaged $0.55 \mathrm{Wm}^{-2}$ increase on the planetary scale. In the clear-sky scenario these numbers increase to 34.9 and $0.97 \mathrm{Wm}^{-2}$, respectively. A meltdown only in September, with all other months unaffected, increases the Arctic annually averaged solar absorption by $0.32 \mathrm{Wm}^{-2}$. We examined the net solar flux trends for the Arctic Ocean and found that the areas absorbing the solar flux more rapidly are the North Chukchi and Kara Seas, Baffin and Hudson Bays, and Davis Strait. The sensitivity of the Arctic absorbed solar flux on sea-ice extent and cloud amount was assessed. Although sea ice and cloud affect jointly the solar flux, we found little evidence of strong non-linearities.
\end{abstract}

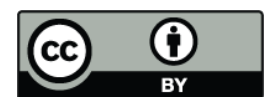

Correspondence to: C. Matsoukas (matsoukas@aegean.gr)

\section{Introduction}

Satellite measurements provide continuous, spatial coverage on Arctic sea-ice extent, starting in 1978. Since then, the Arctic sea-ice extent has been decreasing at a rate of $2.6 \pm 0.6 \%$ per decade (Lemke et al., 2007). Climatologically, Arctic sea-ice extent takes its maximum values in March and its minimum ones in September. Serreze et al. (2007) examined the behaviour of sea-ice cover under changing climatic conditions, with General Circulation Models (GCMs) used in the Intergovernmental Panel on Climate Change Fourth Assessment Report (IPCC AR4), driven with the Special Report on Emissions Scenarios (SRES). They found that for the A1B scenario (in which atmospheric $\mathrm{CO}_{2}$ reaches 720 parts per million by 2100), half of the GCMs reach September ice-free conditions by 2100 . However, the September 2007 record ice extent minimum (Comiso et al., 2008) sparked discussions on summer Arctic total sea-ice melt occurring possibly earlier this century (Stroeve et al., 2008). September 2008 was marked by the second lowest level in sea-ice extent since satellite measurements have begun (NSIDC, 2008).

The Earth radiation budget research community is very interested in the diminishing Arctic sea-ice extent, because of its disproportionate surface forcing on the absorbed solar radiation. By "surface forcing" of the sea ice in this study, we mean the surface fluxes with sea ice absent from the system, minus the same fluxes when sea ice is present, without any consideration for feedbacks. Note that this definition of forcing is different than the one in IPCC, in two ways. First, IPCC examines the flux difference at the tropopause, while we only look at the surface. Second, the IPCC forcing is the difference between the factor present and the factor absent, while ours is the other way round. Therefore, the sea-ice

Published by Copernicus Publications on behalf of the European Geosciences Union. 
forcing we calculate here is always positive, even though sea ice is a cooling factor for the Earth system.

The now well-studied ice-albedo feedback mechanism accelerates ice melting, due to the smaller albedo of the exposed ocean surface and consequently the larger absorbed solar flux values. The changing ice cover can have an effect on the radiative budget which is similar to the greenhouse gases forcing (2.63 $\mathrm{Wm}^{-2}$, as given by Forster et al. (2007), or $2.43 \mathrm{~W} \mathrm{~m}^{-2}$ as given by Vardavas and Taylor (2007)). For example, Stone et al. (2002) examined the advance of snowmelt dates in Barrow, Alaska, and found an 8-day advance between 2000 and the mid-1960s. The resulting change in the ground albedo, has caused a local annual net radiative forcing increase of $2 \mathrm{Wm}^{-2}$. Several other authors (Kuang and Yung, 2000; Aizen et al., 1997; Groisman et al., 1994) report similar perturbations in the radiative budget and argue that significant warming over Northern Hemisphere areas can be attributed to them. The existence of negative cloud feedbacks is also possible. For example, increased evaporation in the warming world may increase cloud cover, which in turn will decrease the net solar flux, decreasing the temperature and increasing the sea-ice extent. However, feedbacks along these lines depend on many cloud characteristics and are substantially less well studied and understood than the ice-albedo feedback.

Recent investigations of Arctic radiation climatology by ground or satellite observations are relatively few (Wang and Key, 2005a; Serreze et al., 1998). Liu et al. (2005) performed a comparison of two satellite products and two numerical weather prediction reanalyses against observational data from the Surface Heat Budget of the Arctic Ocean (SHEBA) experiment. They concluded that satellite-based analyses can provide downward shortwave fluxes with an accuracy of $10-40 \mathrm{Wm}^{-2}$. Trends of the radiation field and of the cloud radiation forcing are reported by Wang and Key (2005b). In their study, it appears that poleward of $60^{\circ} \mathrm{N}$ no statistically significant trend is derived for the net shortwave flux between 1982-1999. On the contrary, over the same area the annual shortwave cloud forcing trend was $-0.32 \mathrm{Wm}^{-2}$ per year (signifying increasing cooling by clouds). There is no contradiction here, because "during the sunlit part of a year, the decreases in sea-ice extent and albedo that result from surface warming modulate the increasing cloud cooling effect, resulting in little or no change in the surface radiation budget". The warming effect of the retreating sea ice is at least partially compensated by the increasing cooling effect of the clouds.

Recently, Gorodetskaya et al. (2008) used three GCMs to examine the effect that sea ice and cloud parameters have on the Arctic shortwave radiation budget now and through the 21 st century. They report that although the GCMs reproduce broadly the observed characteristics of the shortwave budget, there were large differences in the generated cloud phase and cloud fraction, both between the GCMs and with SHEBA observations. Of course, these differences affected the radi- ation budget. Also, the degree of compensation between the forcings of the sea ice and the cloud amount varies among the three GCMs.

The aim of this study is to investigate some facets of the role Arctic sea ice plays on the Earth's surface absorbed (net) solar radiation. We address the sensitivity of the net solar radiation on the hypothetical scenario of an ice-free Arctic ocean. We thus determine the bounds of the Arctic sea-ice forcing on the net surface solar flux. We also present time series of the Arctic net solar radiation for the period July 1983 June 2007 and show the spatially resolved trend. A study on a similar subject by Perovich et al. (2007) was published recently, combining satellite-derived ice data, field albedo observations, and fluxes from ERA-40 reanalysis and forecasts, to compute the absorbed solar energy in the Arctic open water. We feel that we improve on the study of Perovich et al. (2007) on the following points: First, we don't rely on reanalyses for our solar fluxes. Liu et al. (2005) demonstrated that the ERA-40 surface downwelling shortwave fluxes can differ considerably from the measured values from SHEBA. On the other hand, they found that fluxes based on satellite data, such as the International Satellite Cloud Climatology Project (ISCCP-FD) and Cloud and Surface Parameter Retrieval (CASPR)/Arctic Regional Climate Model Intercomparison Project (ARCMIP), performed better. In our study we also use satellite data from ISCCP-D2 to produce surface downwelling shortwave radiation fluxes. Second, we model the solar energy input not only on open water, but also on sea ice. Third, our ocean albedo is not fixed at 0.07 , but is modelled using Fresnel reflection as a function of the solar zenith angle and corrected for a non-smooth surface. On the other hand, a drawback in our approach relative to that of Perovich et al. (2007) is the lower spatial resolution of $2.5^{\circ} \times 2.5^{\circ}$, dictated by the input data to our model.

\section{Model description}

The deterministic 1-D spectral radiative transfer model used here was developed from a radiative-convective model (Vardavas and Carver, 1984). The incoming solar irradiance conforms to the spectral profile of Thekaekara and Drummond (1971) and corresponds to a solar constant $S_{0}$ of $1367 \mathrm{Wm}^{-2}$ (Willson, 1997; Hartmann, 1994). The model makes adjustments for the elliptical Earth orbit and apportions $69.48 \%$ of the incoming spectral irradiance to the ultra violet - visible near infrared (UV-Vis-NIR) part $(0.20-1 \mu \mathrm{m})$ and $30.52 \%$ to the infrared (IR) part $(1-10 \mu \mathrm{m})$. Then, the radiative transfer equations are solved for 118 separate wavelengths for the UV-Vis-NIR part and for 10 bands for the IR part, using the Delta-Eddington method of Joseph et al. (1976). For a more detailed model description the reader is referred to Hatzianastassiou et al. (2004a,b, 2007a,b).

The model takes into account Rayleigh scattering due to atmospheric gas molecules, as well as absorption from 
$\mathrm{O}_{3}, \mathrm{O}_{2}, \mathrm{CO}_{2}, \mathrm{H}_{2} \mathrm{O}$, and $\mathrm{CH}_{4}$. The $\mathrm{O}_{3}$ column amount is taken from the Television Infrared Observational Satellite (TIROS) Operational Vertical Sounder (TOVS). The water vapour and temperature vertical atmospheric profiles come from the National Centers for Environmental Prediction (NCEP)/National Center for Atmospheric Research (NCAR) global reanalysis project (Kistler et al., 2001). Complete aerosol data are provided by the Global Aerosol Data Set (GADS) (Köpke et al., 1997). The model also needs input on cloud properties, such as cloud amounts, and cloud optical thickness. This is provided in $2.5^{\circ} \times 2.5^{\circ}$, monthly resolution for 15 cloud types by ISCCP (Rossow and Schiffer, 1999). ISCCP initially summarises $30 \mathrm{~km} \times 30 \mathrm{~km}$ cloud data every $3 \mathrm{~h}$ on an equal-area map grid with $280 \mathrm{~km}$ resolution and merges the results from separate satellites with atmospheric and ice/snow datasets to produce global coverage at each time. The Stage D2 data product is produced by further averaging over each month, first at each of the eight $3 \mathrm{hr}$ time slots and then over all time slots. The cloud top temperature is derived from the infrared radiances, while the cloud top pressure from the vertical temperature profile of the atmosphere. We use the cloud optical thicknesses in the visible $(0.6 \mu \mathrm{m})$, retrieved in ISCCP after comparison of the visible radiances with pre-calculated values from their radiative model. For more details on ISCCP polar clouds, the reader is referred to Hatzianastassiou et al. (2001).

ISCCP also provides surface data, such as snow/ice cover and albedo. According to the ISCCP documentation: on the ice data product: "The original sea ice dataset used by ISCCP through 1991 is a digital version of the weekly analyses prepared by the US Navy as paper maps since 1972. The weekly sea ice analyses combine data from shore station reports, ship reports, aerial reconnaissance and satellite image analysis. The satellite-based information constitutes $90-98 \%$ of the total and comes from visible/infrared imagery from the operational weather satellites and microwave imagery from experimental and operational satellites (when available). If new data do not arrive during the analysis cycle, older values are retained. In 1993, NOAA ceased preparation of the digital sea ice cover dataset for an indefinite period; the last year of data available is 1991. The new sea ice dataset is based solely on a daily analysis of microwave measurements from the SSM/I on US Air Force DMSP weather satellites using the "NASA Team" algorithm (Cavalieri et al., 1984). Snow cover is estimated by daily visual inspection of all available visible band satellite imagery; the presence of snow at a particular location represents the latest cloud-free observation of that site available within the week. Unilluminated portions of the polar regions are assumed to be completely snowcovered". Based on the above quotation, wintertime sea ice is not directly observed, but rather assumed to be there. Although this can introduce errors in the winter sea-ice extent, it will not have any effect on the object of this study, which is the sea-ice effect on the net solar flux in the Arctic, because of the minimal solar flux values during the winter season.

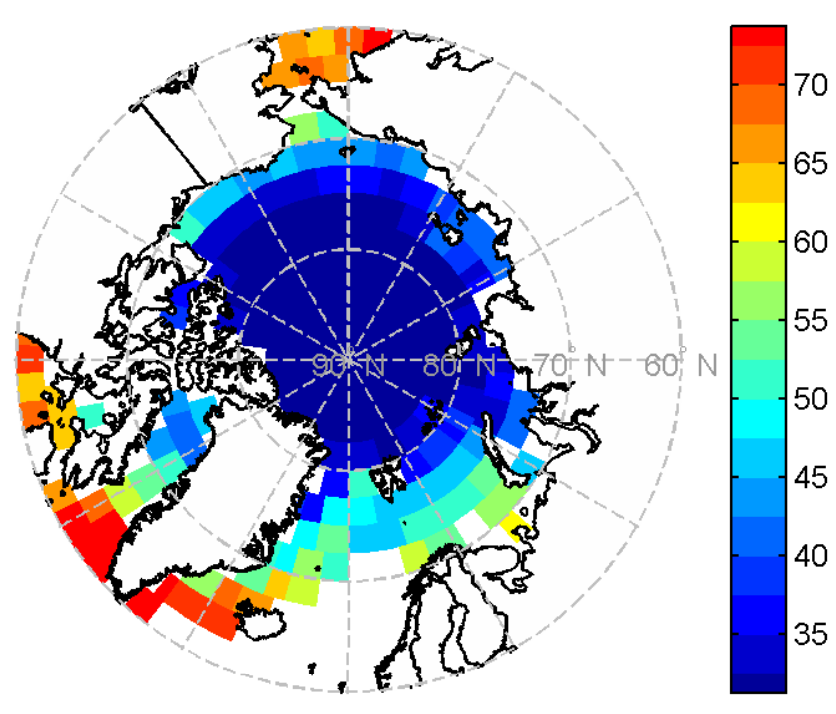

Fig. 1. Long-term average all-sky net solar flux $\left(\mathrm{Wm}^{-2}\right)$ for the Arctic Ocean, as given by our model for the period July 1983-June 2007. Seasonally freezing areas are included in the analysis, while ice-free locations throughout the year are masked out.

Output from the model includes the following set of solar fluxes: incoming at the Top Of Atmosphere (TOA), reflected at TOA, net (incoming minus reflected) at TOA, downwelling at the surface (global), reflected at the surface, net (downwelling minus reflected) at the surface. The focus of this study is the solar energy absorbed by the Arctic ocean, ice-covered or not, which corresponds to the net solar flux at the surface. This net solar flux long-term average for the study period of July 1983-June 2007 is presented in Fig. 1, where we have masked out land and ice-free ocean.

\section{Results and discussion}

The physical quantities, whose temporal characteristics influence most the Arctic sea-ice radiative forcing through their effect on planetary albedo, are sea ice and cloud cover. We will examine separately the ISCCP-D2 data for these quantities, as well as the effect they have on the net solar flux on the surface. The sea-ice extent and its effect will be presented in Sect. 3.1, where we will also give an upper bound for the seaice forcing on the absorbed solar radiation. The cloud cover and its effect is presented in Sect. 3.2, as well as our estimate on sea-ice forcing. In Sect. 3.3 we describe an experiment which gives a lower bound for the sea-ice forcing.

\subsection{Clear-sky model}

We already mentioned that the ISCCP-D2 dataset contains data on sea ice and snow cover for the globe. We use these data to derive a time series of the sea-ice extent for the Arctic between July 1983 and June 2007 (Fig. 2). The time series 


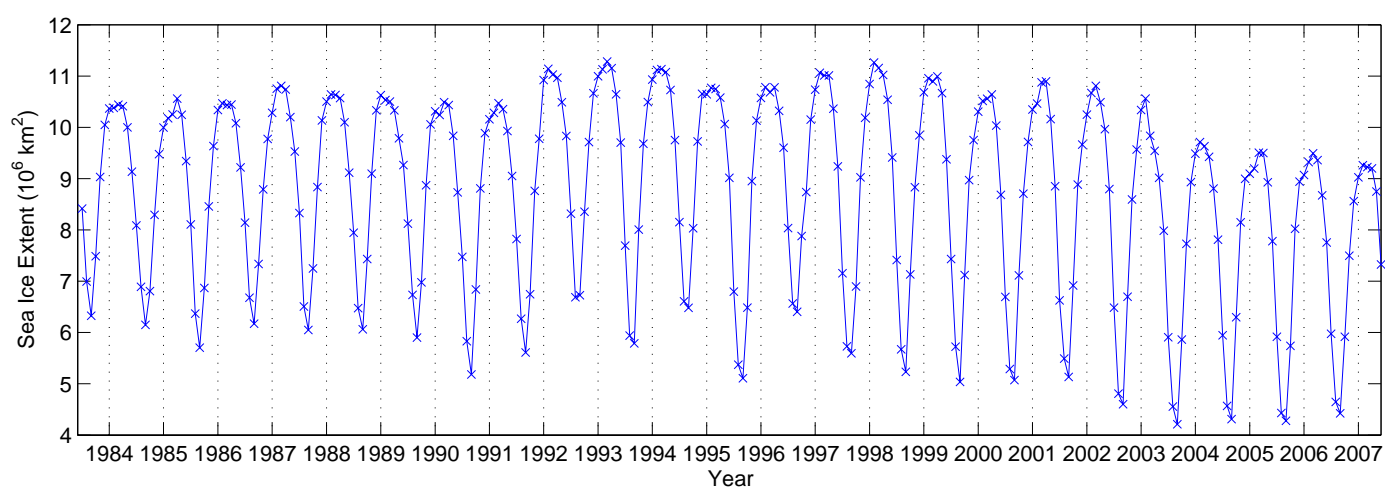

Fig. 2. Spatial extent of the Arctic sea ice (latitude larger than $60^{\circ} \mathrm{N}$ ), as given by ISCCP-D2 from July 1983 to June 2007 . Note the decreasing trend after 1999.

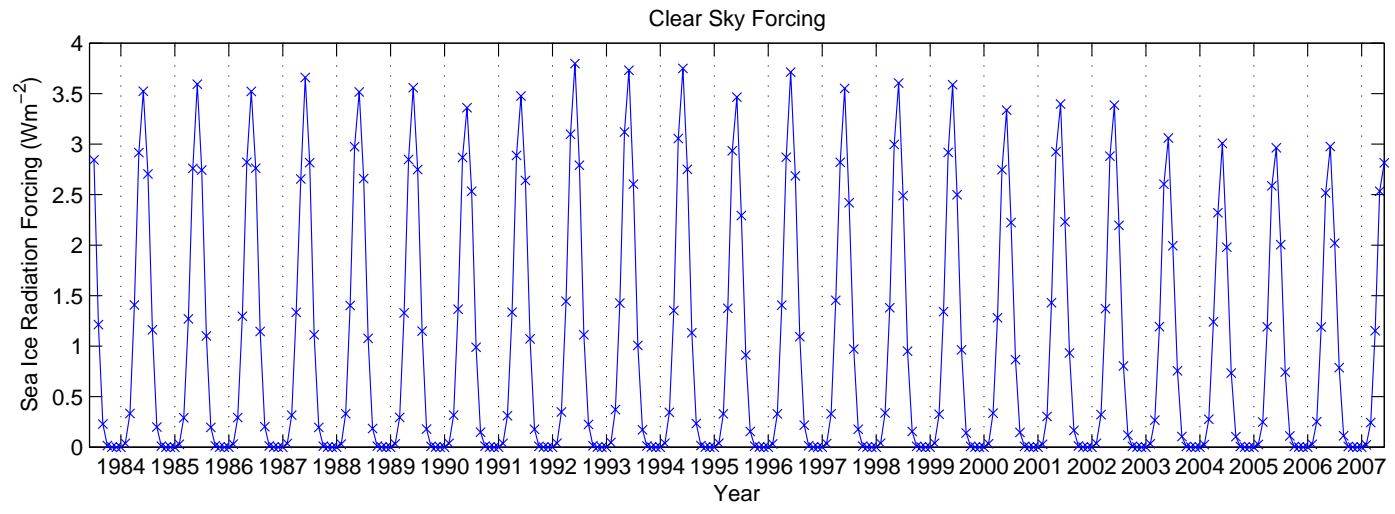

Fig. 3. Clear-sky Arctic sea-ice net surface solar radiation forcing from July 1983 to June 2007, as an average for the whole globe.

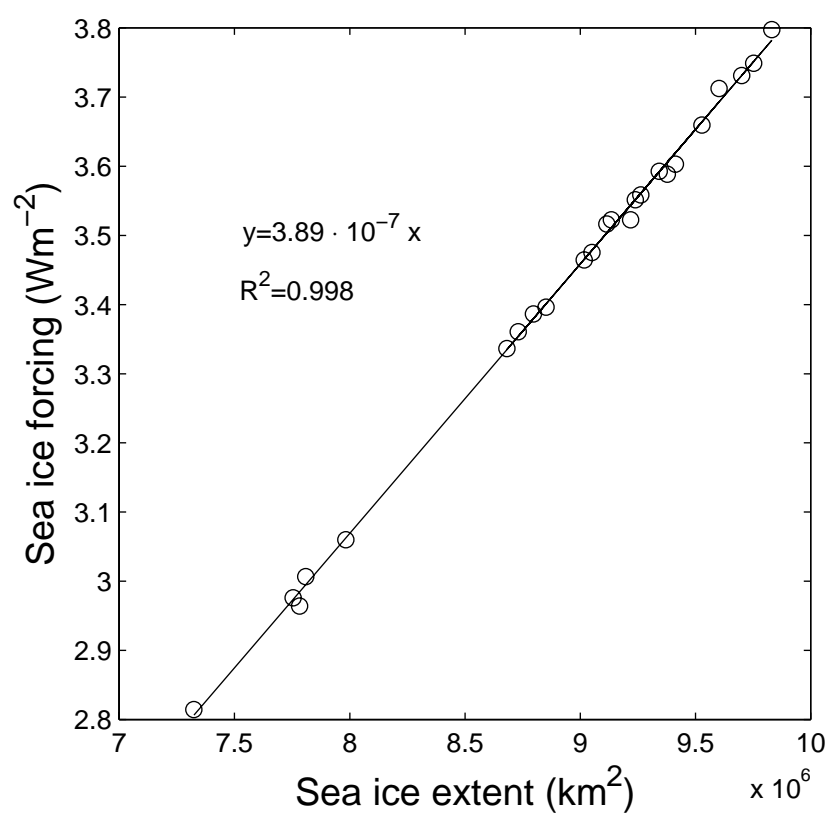

Fig. 4. June sea-ice forcing with respect to June sea-ice extent. expectedly shows sea-ice extent minima in September and maxima around March. There is evidence for a decreasing trend starting in 1999 up to the end of the time series.

Our radiative transfer model is run in clear-sky mode by removing the cloud layers from our modelled atmospheric structure. Running the model once with the prescribed sea ice and once without it, we can see the effect ice has on the net solar flux at the surface. This effect is the sea-ice radiation forcing, whose time series we present in Fig. 3. Its calculation includes any $2.5^{\circ} \times 2.5^{\circ}$ cell northward of $60^{\circ} \mathrm{N}$, reported as sea-ice covered (even partially) by ISCCP, at least for one month in the period July 1983-June 2007. This area is shown with the coloured pixels in Fig. 1. The forcing for the Arctic Ocean surface is the sum of all $2.5^{\circ} \times 2.5^{\circ}$ cell forcings, divided by the Arctic Ocean surface area, equal to $14056000 \mathrm{~km}^{2}$. If this sum is instead divided by the planet surface area, we derive the forcing for the whole planet. The sea-ice radiation forcing values shown here are global averages, i.e. they correspond to solar flux changes averaged over the whole planet, even though the change is geographically confined to the Arctic.

The clear-sky sea-ice forcing reaches its maximum values in June and its minimum in the winter, following the maxima 


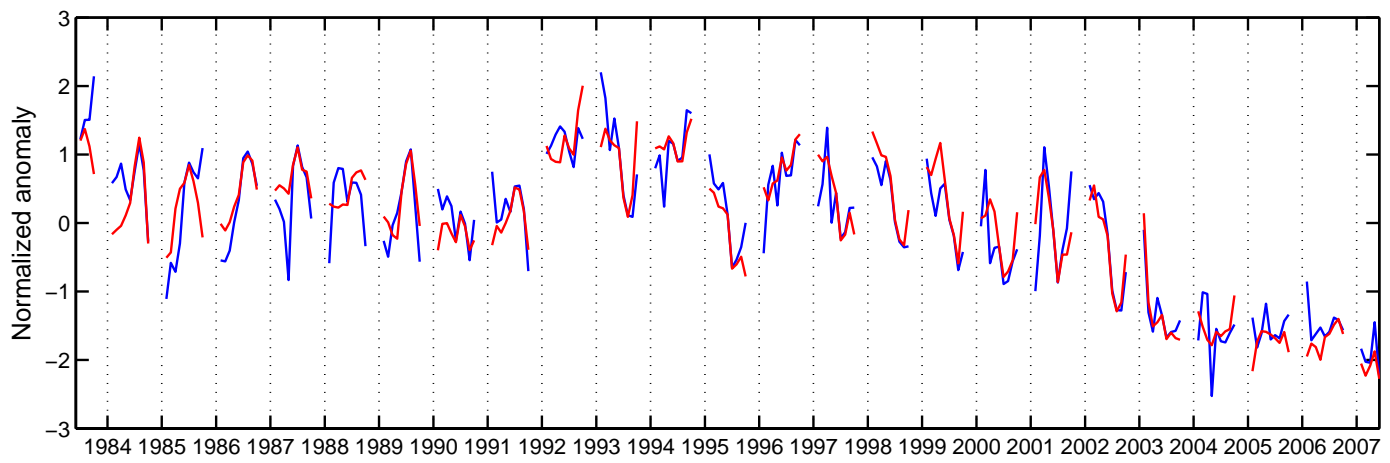

Fig. 5. Normalised anomaly time series for the sea-ice extent (red) and its clear-sky forcing on the surface net solar flux (blue).

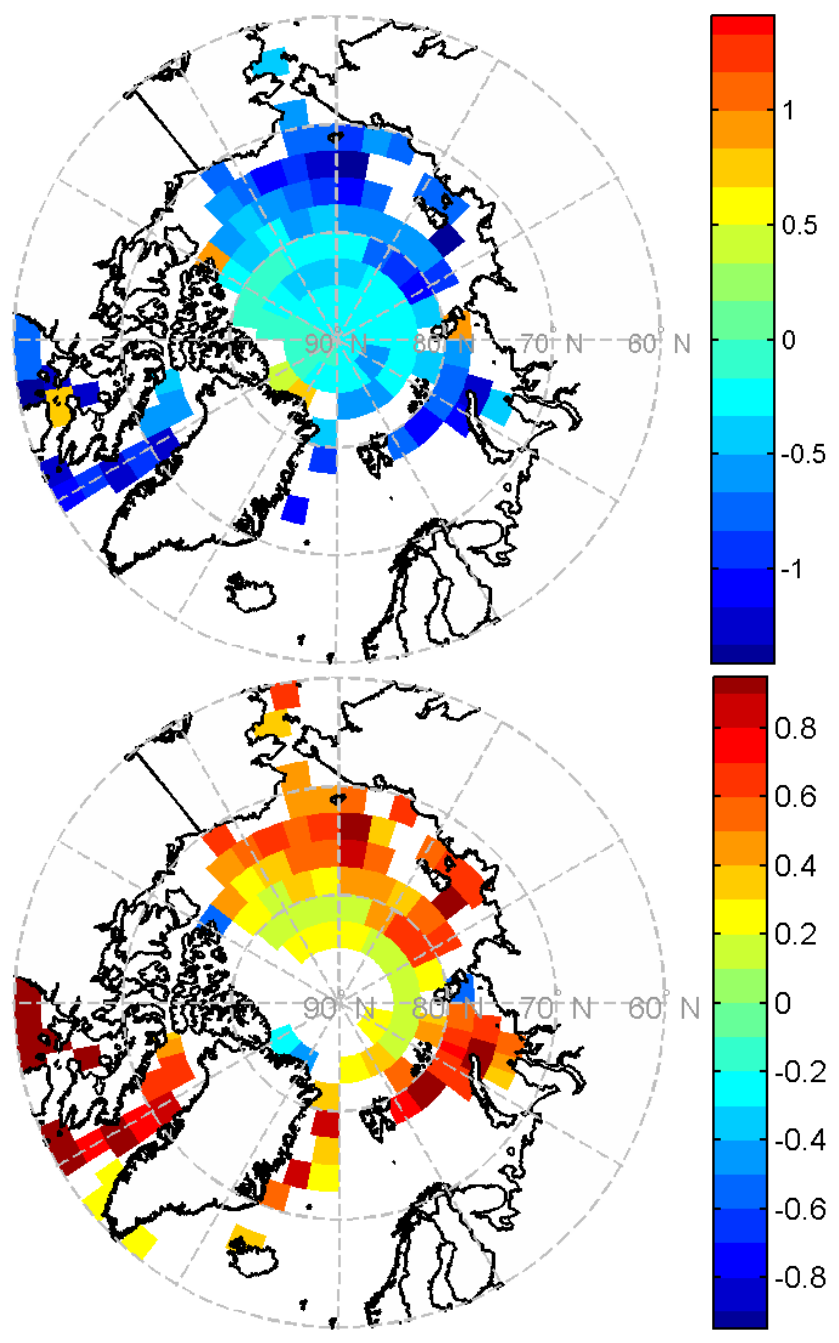

Fig. 6. Statistically significant $(95 \%$ confidence) trends between 1984-2006. On the left, the annual sea-ice extent (\% per year). On the right, the annual clear-sky net solar flux $\left(\mathrm{Wm}^{-2}\right.$ per year). and minima in the downwelling solar flux in the Arctic. The maximum values in June are around $3.5 \mathrm{Wm}^{-2}$, meaning that in the extreme case of total ice pack disappearance, the Earth system will absorb larger solar fluxes by $3.5 \mathrm{Wm}^{-2}$ each June. The annually averaged clear-sky forcing for the globe is $0.97 \mathrm{Wm}^{-2}$. This is the increase in net solar radiation absorbed by the Earth system, which would be caused by a hypothetical ice-free Arctic ocean at least between March and November. The existence of ice between December and February is of little importance as far as solar forcings are concerned. If instead of averaging the annual clear-sky seaice forcing globally, we average it over the $14056000 \mathrm{~km}^{2}$ of the entire Arctic Ocean, its value becomes $34.9 \mathrm{Wm}^{-2}$.

The temporal behaviour of the clear-sky sea-ice forcing is controlled by the surface downwelling solar flux and the seaice extent, while effects of other climatic quantities are negligible. The seasonal behaviour is controlled by the downwelling solar flux, with the maximum sea-ice forcing values occurring in June, when the solar flux is also maximum. On the other hand, the interannual behaviour is affected by the sea-ice extent. In Fig. 4 we plot for all months of June, i.e. for the maximum values of sea-ice forcing, the sea-ice net solar forcing against sea-ice extent. The twenty four points, corresponding to the twenty four years of the study, fall around a straight line, with an $R^{2}$ value of 0.998 . The control of the sea-ice extent on the clear-sky forcing is manifested also in Fig. 3, if we note that the decreasing trend of the forcing after 2001, correlates well with the decreasing values of the June sea-ice extent in Fig. 2.

The temporal trends of the sea-ice extent and its clear-sky forcing, as well as their cross correlation, can be examined better if we present their normalised anomalies. These consist of their deseasonalised time series, normalised by the standard deviation of the interannual variability for each specific month. For example, the normalised anomaly of June 2008 is the difference between the June 2008 value and the mean of all June values, divided by the standard deviation of all June values. In Fig. 5 the red and blue lines correspond to the normalised anomalies of the sea-ice extent and its forcing, respectively. The period between November and January 


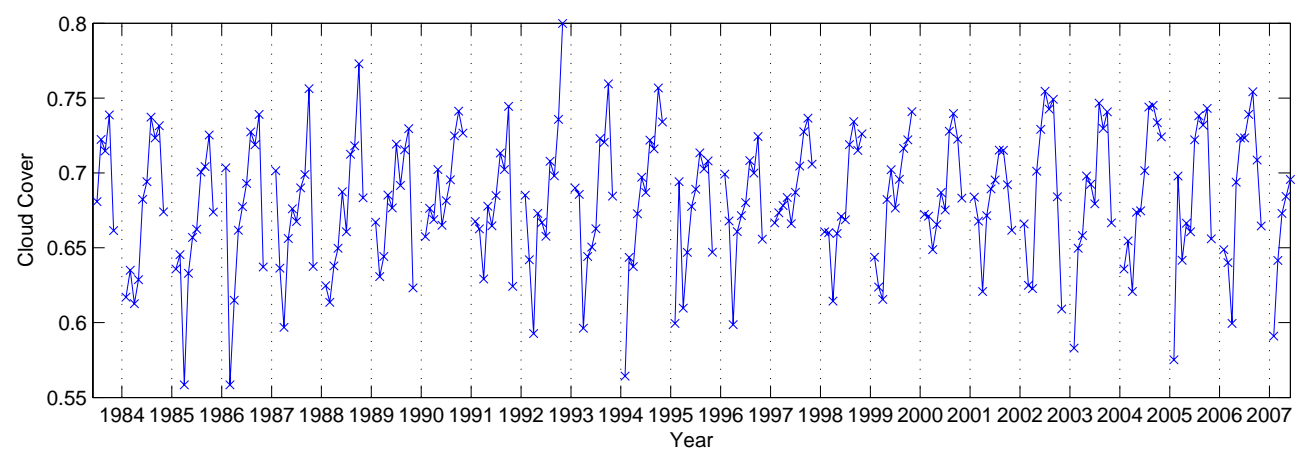

Fig. 7. Total Arctic cloud cover (latitude larger than $60^{\circ} \mathrm{N}$ ), as given by ISCCP-D2 from July 1983 to June 2007. Missing data correspond to poor satellite coverage due to Polar night conditions.

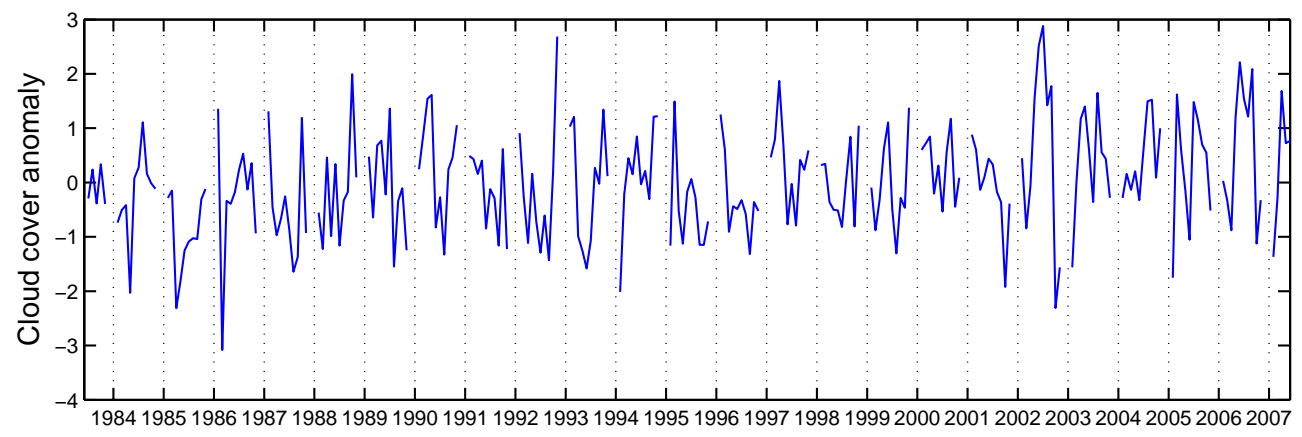

Fig. 8. Normalised anomaly time series for the Arctic cloud cover (latitude larger than $60^{\circ} \mathrm{N}$ ). Missing data correspond to poor satellite coverage due to Polar night conditions.

(inclusive) for every year is left blank in this plot, because it corresponds to problematic sampling of ice cover. Also, the zero winter values of the forcing create spurious features in the plot. The decreasing trend after 1999 is apparent, as well as their large cross-correlation. The cross corelation is quantified by $R^{2}=0.827$ for the whole series, while $R^{2}$ takes the value 0.998 only for June as we already have seen.

The Arctic ice retreat and therefore the ice forcing is not spatially uniform. In order to see the spatial pattern of their change, we take each $2.5^{\circ} \times 2.5^{\circ}$ cell, create its annual time series between 1984 and 2006, and then fit a least-squares line. The sign of the slope is a reflection of the increasing or decreasing trend in the ice extent or the net solar flux at the cell. Each slope is calculated with a $95 \%$ confidence interval. If the slope does not change sign throughout the $95 \%$ interval (the interval does not contain the zero value), the trend is considered statistically significant and is presented in Fig. 6.

Generally, the areas with statistically significant trends in sea-ice forcing are the same areas with statistically significant trends in sea-ice extent, especially where the trends are large. However, where the trends are small, we may have statistical significance in one but not the other of the two quantities. For example at the North Pole we have a small (but statistically significant) decreasing trend in sea-ice extent, re- sulting from partial melting from 1999 onwards. However, although poleward of $70^{\circ} \mathrm{N}$ we find increasing trends in the net solar flux, these increases are small and not statistically significant. The largest trends are seen at the North Chukchi and Kara Seas, in agreement with Perovich et al. (2007), with values around $1 \mathrm{Wm}^{-2} \mathrm{yr}^{-1}$. Large trends are found also at Baffin Bay, Hudson Bay and Davis Strait, although in Perovich et al. (2007) the corresponding trends are smaller.

There is the exception of a few cells with increasing seaice cover and of course decreasing net solar flux. Regardless of statistical significance, $92 \%$ of all cells had a negative seaice extent trend, while only $8 \%$ had an increasing one. The cells with increasing trends are generally scattered and not statistically significant at the $95 \%$ confidence level. There is some agreement with Perovich et al. (2007) who found a belt of increasing sea ice on the northern edge of the Canadian Archipelago, but in our coarser dataset this feature is not clearly discernible. There are also a few cells with positive trends close to Severnaya and Novaya Zemlya, in Bering Sea and Hudson Bay. This is loosely supported by Fig. 1 of Stroeve et al. (2005), showing increases in sea-ice cover for Septembers of 2003 and 2004 in the Canadian Archipelago, Barents, Kara and Laptev Seas. However this agreement is circumstantial and based on sporadic data. 


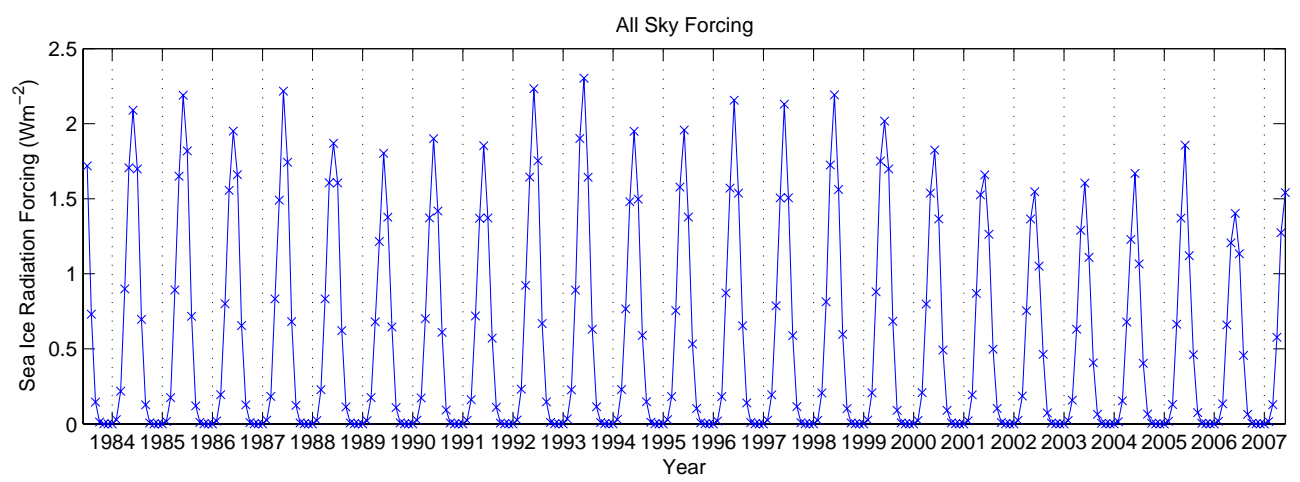

Fig. 9. All-sky Arctic sea-ice radiation forcing from July 1983 to June 2007.

\subsection{All-sky model}

The ISCCP-D2 dataset reports cloud cover for 15 cloud types over the globe. The sum of the individual cloud type cover poleward of $60^{\circ} \mathrm{N}$ is defined in this study as the Arctic total cloud cover. Its values range between zero (clear-sky) and one (totally cloudy sky). The Arctic cloud series is shown in Fig. 7, where we can see gaps in the ISCCP-D2 cloud data between October and February, during the polar night. We note again that the effect of the missing winter cloud data on the radiation forcing is minimal, due to the low solar flux values this time of year. The interannual behaviour of cloud cover can be better visualised by the presentation of its normalised anomaly in Fig. 8. There seems to be a tendency for increasing cloud cover in our study period. Indeed, the least squares line in Fig. 8 has a statistically significant trend at the $95 \%$ confidence level, with a value of $0.30 \%$ (absolute cloud cover) per year. However, Wang and Key (2005b) detected a statistically not significant decreasing trend in Arctic cloud amount. All presented forcing values up to now were for the clear-sky case. If we include clouds in our analysis the surface solar downwelling fluxes will be smaller. As a result, the net solar forcing values will also be smaller. The time series of the all-sky net solar forcing is shown in Fig. 9. As expected, by comparison with Fig. 3, we can see that the forcing for the all-sky case is indeed smaller than for the clearsky. The temporal behaviour of the time series here is also different than for the clear-sky, a fact that highlights the impact of clouds. One example is the noticeable decrease for the all-sky June 1994 forcing relative to June 1993, while for the clear-sky case, the 1994 and 1993 forcings are comparable. The reason here is the increase in total cloud cover from June $1993(65.0 \%)$ to June 1994 (69.7\%). As another example, the all-sky 2005 forcing in June increased relative to 2003, while in the clear-sky case we observe the opposite. Comparing June cloud cover for 2003 and 2005, we see a decrease from $69.24 \%$ to $66.06 \%$, large enough to offset the effect of the decreasing sea-ice extent on the net solar forcing.
The sea-ice forcing on the net solar flux for the all-sky case takes its maximum values $\left(1.5-2.5 \mathrm{Wm}^{-2}\right)$ in June. The annually averaged all-sky sea-ice forcing value is $0.55 \mathrm{Wm}^{-2}$, roughly half that of the clear-sky case. According to our results, if all Arctic ice disappears completely and the cloud amount remains unaffected, the planet's surface will absorb $0.55 \mathrm{~W} \mathrm{~m}^{-2}$ more solar flux than it did during our study period of July 1983 to June 2007. If our region of interest is the Arctic Ocean instead of the entire globe, the annual all-sky sea-ice forcing becomes $19.7 \mathrm{Wm}^{-2}$.

In another experiment, if we assume that everything stays the same with the exception of September total Arctic disappearance, the forcing for the Arctic region will be $3.84 \mathrm{Wm}^{-2}$ for the month of September and $3.84 / 12=0.32 \mathrm{Wm}^{-2}$ for the annual average. The localised radiative effect of a September ice-free Arctic Ocean is eight times smaller than the forcing by the enhanced greenhouse effect $\left(2.5 \mathrm{Wm}^{-2}\right)$.

The normalised anomaly of the sea-ice extent and its forcing are presented in Fig. 10 with red and blue lines respectively. We can see a decreasing trend after 1999 of similar magnitude to Fig. 5. The correlation with the sea-ice extent here is weaker $\left(R^{2}=0.702\right)$, due to the cloud effects.

The trends of the all-sky net solar flux for each cell are calculated similarly to the clear-sky case and are shown in Fig. 11. The spatial pattern is much less clear here. Fewer cells have statistically significant trends and even for these, the values are smaller. Again, there are widespread positive net solar flux trends poleward of $70^{\circ} \mathrm{N}$ (not shown), but the statistically significant trends at the $95 \%$ confidence interval are the ones shown in Fig. 11. North Chukchi Sea is characterised with increasing all-sky net solar flux, as found also by Perovich et al. (2007). However, the trend we estimate is considerably lower than theirs. They give values as high as $4 \%$ per year, while ours are around $0.5 \mathrm{Wm}^{-2}$ per year, which corresponds to $1.5 \%$ per year if we consider all-sky net annual solar fluxes close to $35 \mathrm{Wm}^{-2}$ in the area. Even our clear-sky net solar flux trend for North Chukchi Sea is not larger than $2 \%$ per year. This disagreement stems from the 


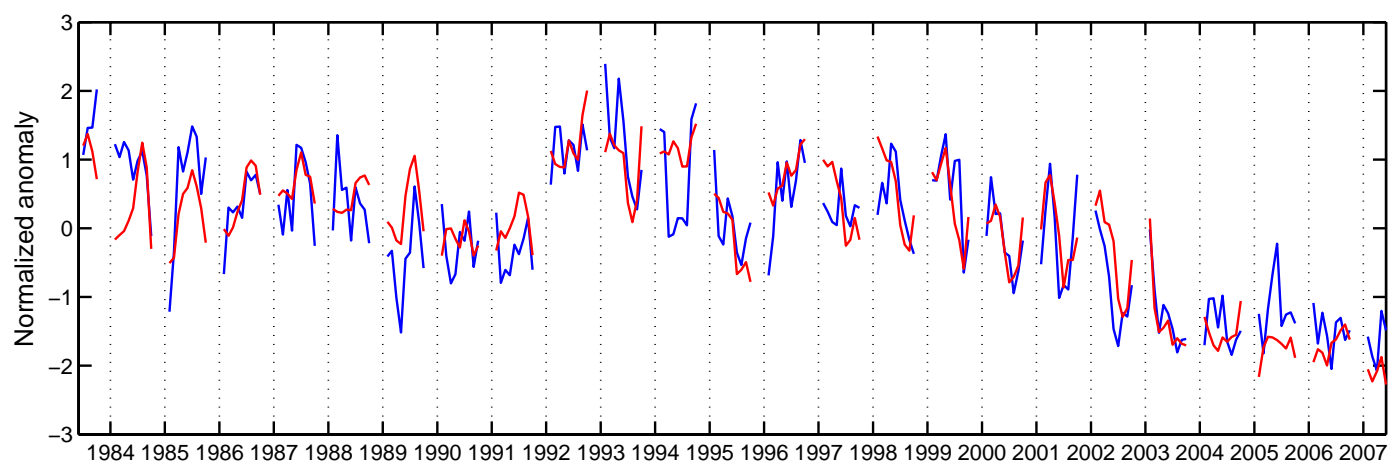

Fig. 10. Normalised anomaly time series for the sea-ice extent (red) and its all-sky forcing on the surface net solar flux (blue).

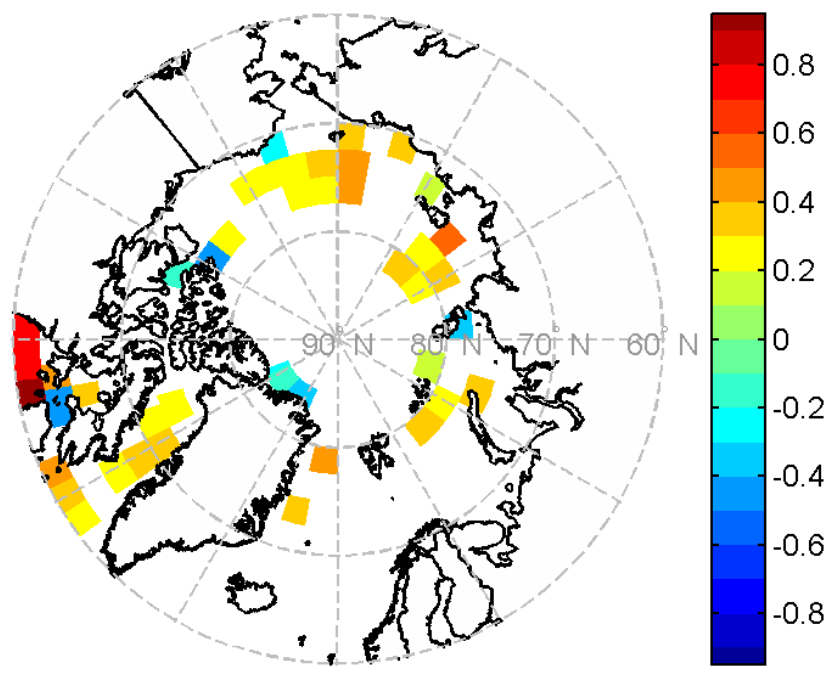

Fig. 11. Statistically significant trends $\left(\mathrm{Wm}^{-2}\right.$ per year) for the all-sky net solar flux between July 1983-June 2007.

different data sources for the analyses. Perovich et al. (2007) take their fluxes from the NCEP/NCAR reanalysis, while our fluxes are based our radiative transfer model, run with ISCCP-D2 data as input. Their analysis period (1979-2005) is also slightly different than ours (July 1983-June 2007).

\subsection{Overcast-sky model}

A scenario worth investigating is the possible increase of cloud cover in the Arctic. The physical basis for this negative feedback is the idea that a more humid atmosphere in a warming world could result in increased cloud amounts. Should this happen, it will reduce the forcing of the retreating Arctic sea ice. If we run our model using a totally overcastsky we can produce a lower bound for the forcing by a meltdown of the Arctic sea ice. To this end, we prescribe a cloud cover of $100 \%$, keeping the same partitioning between low, middle, and high clouds as given by ISCCP-D2, and run the model once with the Arctic sea ice absent and once with it present. The difference in the net surface downwelling solar radiation is the sea-ice forcing under an overcast sky. The overcast-sky forcing, shown in Fig. 12, is smaller than the clear-sky and all-sky cases.

Also in the totally overcast case, the maximum forcings occur in June, but with significantly smaller values (0.6$1.3 \mathrm{Wm}^{-2}$ ) compared to the clear-sky or all-sky cases. The annually averaged sea-ice forcing over the whole planet is $0.28 \mathrm{Wm}^{-2}$, while the annually averaged forcing over the Arctic Ocean is $10.2 \mathrm{Wm}^{-2}$. The normalised anomaly of the sea-ice extent and its forcing is not presented here, but is quite similar to Fig. 10 of the all-sky case.

\section{Sensitivity analysis}

Sea ice affects the absorbed radiation in more ways than one. The primary effect is the reflection of the downwelling radiation back to the atmosphere and the subsequent reduction of absorbed surface radiation. A secondary effect is the rereflection of the now upwelling radiation on the cloud layer and its redirection to the surface. This secondary effect of the ice causes multiple reflections between the sea ice and the clouds, increasing the values of downwelling radiation and thus the absorbed surface radiation. As a matter of fact, the downwelling solar radiation is quite sensitive to the existence of ice, due to multiple reflections between ice and clouds. The net sea-ice effect, after we consider both the competing primary and secondary effects, is negative, i.e. it leads to a reduction in absorbed solar flux. In the previous section we examined the most basic radiation effects of sea ice and cloud amount. In order to further investigate their interaction, we now perform a net solar flux forcing sensitivity analysis, with respect to the sea-ice extent and the cloud amount.

In more detail, for one year (randomly selected to be 1991) we change independently the sea-ice extent and the cloud amount by $0 \%,-5 \%$, and $5 \%$. We should note that in $2.5^{\circ} \times 2.5^{\circ}$ cells with almost total sea-ice or cloud coverage, an increase of $5 \%$ in cover would cause it to exceed $100 \%$. In 


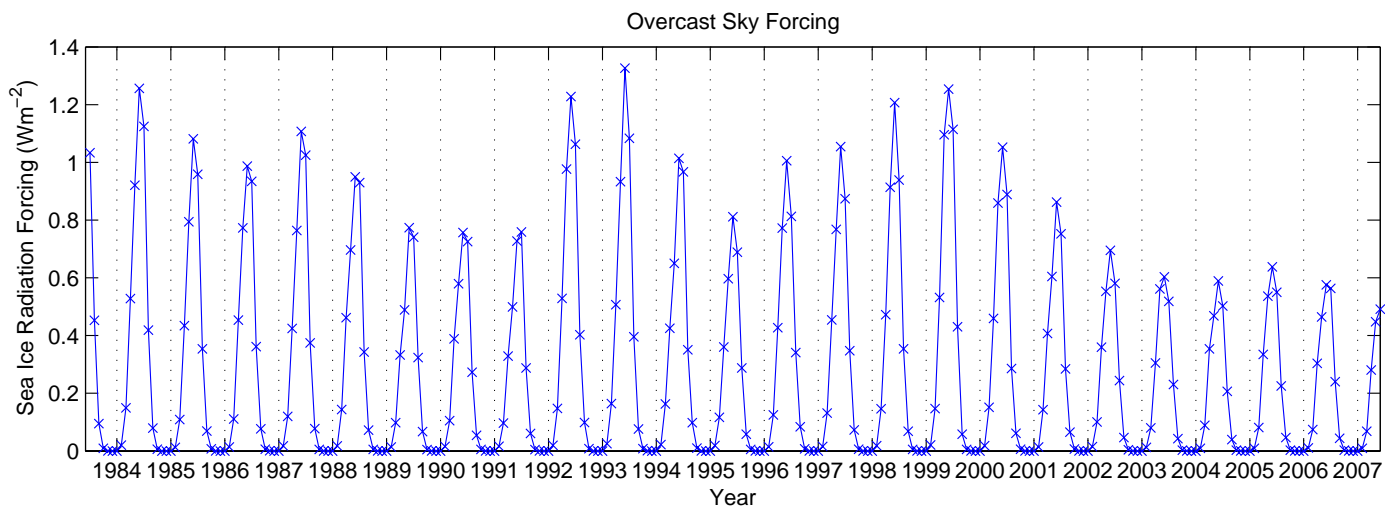

Fig. 12. Overcast-sky Arctic sea-ice radiation forcing from July 1983 to June 2007.

Table 1. Sea-ice forcing sensitivity analysis with respect to sea-ice extent and cloud cover. Percentage values show the forcing change compared to the control case.

\begin{tabular}{|c|c|c|c|c|}
\hline & & \multicolumn{3}{|c|}{ Cloud cover } \\
\hline & & $0 \%$ & $-5 \%$ & $5 \%$ \\
\hline \multirow{3}{*}{ 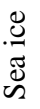 } & $0 \%$ & $0 \%$ & $4.7 \%$ & $-4.7 \%$ \\
\hline & $-5 \%$ & $-6.0 \%$ & $-1.5 \%$ & $-10.4 \%$ \\
\hline & $5 \%$ & $3.0 \%$ & $7.7 \%$ & $-1.8 \%$ \\
\hline
\end{tabular}

these cases the values were capped at $100 \%$. Three configurations of two physical quantities give us $3^{2}=9$ separate experiments, with the experiment of $0 \%$ change in both sea-ice extent and cloud cover being our control case of the all-sky run presented in Sect. 3.2. For each one of the 9 experiments our model was run twice, once with the sea ice removed and once with the sea ice present. The net surface solar flux difference between the two runs is the surface forcing of the sea ice. The percent change in forcing with respect to the control case is reported in Table 1. The table rows correspond to the changes in sea-ice extent, while the table columns correspond to the changes in cloud cover. The upper left value of $0 \%$ is our unperturbed control case. The $4.7 \%$ value to the right of the control case means that decreasing the cloud cover by $5 \%$, without modifying the sea ice, caused an increase in sea-ice forcing by $4.7 \%$. The $-6.0 \%$ under the control case in Table 1, shows that if we reduce sea-ice extent by $5 \%$, leaving the cloud amount unperturbed, the sea-ice forcing will decrease by $6.0 \%$. The effect of sea ice is asymmetrical in the sense that a 5\% increase has a smaller impact than the 5\% decrease. This is due to the enforced ceiling of $100 \%$ on the sea-ice extent, while there is no enforced minimum value. Such an asymmetry is not found for cloud cover, because there are very few cells with almost total cloud coverage.
Table 2. Sea-ice forcing $\left(\mathrm{Wm}^{-2}\right)$ for the clear-sky, all-sky and overcast-sky cases, estimated as an average over the globe or over the Arctic Ocean.

\begin{tabular}{lccc}
\hline Average & Clear-sky & All-sky & Overcast-sky \\
\hline Global & 0.97 & 0.55 & 0.28 \\
Arctic & 34.9 & 19.7 & 10.2 \\
\hline
\end{tabular}

In each row of the Table, decreasing (increasing) cloud amount by $5 \%$, leads to an increase (decrease) of the forcing by $4.4-4.7 \%$ with respect to the leftmost column of unchanged cloud cover. This amount is independent of the seaice extent, as it is approximately the same in every row. As an example for the second row, increasing the cloud cover gives a $-10.4 \%-(-6.0 \%)=-4.4 \%$ change in forcing, while decreasing it gives us a $-1.5 \%-(-6.0 \%)=4.5 \%$ change. Moreover, in all situations with simultaneous changes in sea-ice extent and cloud cover, the effect on the forcing is almost equal to the sum of the effects from the corresponding individual changes. For example, in the case of combined seaice and cloud cover increase by $5 \%$ (bottom right cell of Table 1) the effect on forcing is $-1.8 \%$. The sum of the effects on the forcing from the individual sea-ice and cloud cover changes is $3.0 \%-4.7 \%=-1.7 \%$. Therefore, in the limited context of this sensitivity analysis, we find little indication of significant non-linearity between the sea-ice extent and cloud cover, with respect to their effects on surface absorbed radiation fluxes. Their previously seen complex interplay does not give rise to non-linear effects. Note however that our sensitivity analysis is time independent and this nonlinearity should not be assumed in a prognostic model such as a General Circulation Model. 


\section{Conclusions}

The motivation behind this study was the effect of the retreating Arctic sea ice on the solar energy balance of the planet and the Arctic Ocean. Our main tool was a thoroughly tested radiative transfer model which was run with satellite sea ice and cloud observational data from ISCCP-D2 and other input data from the NCEP/NCAR reanalysis. The study period was July 1983-June 2007, in which a decrease in sea-ice extent after 1999 was evident. Our model produces radiation fluxes at the surface, as well as the top of the atmosphere. However, this work focuses only on surface effects of the sea ice, so only the surface fluxes were used.

We calculated the net solar flux at the Arctic Ocean. Our main interest in this study is the effect of the Arctic sea ice on the absorbed (net) solar flux at the surface, which we term "sea-ice solar forcing" for convenience. The methodology we employed for its estimation consisted of running the radiative transfer model twice, once with the sea ice removed and once with it present. The difference between the two absorbed fluxes is the sea-ice solar forcing. This forcing quantifies the effect of sea ice on the radiation budget of the Arctic, which is the subject of research due to the ice-albedo feedback and its role in climate change.

We computed an interval of possible values for the seaice forcing, depending on the amount of cloud cover over the Arctic. The ice and cloud dataset we used comes from satellite observations processed by ISCCP-D2. The ice and cloud data from ISCCP-D2 give consistent radiation fields at the TOA. We performed three experiments: first with no clouds present (clear-sky), second with cloud data as given by ISCCP-D2 (all-sky), third by setting the cloud cover always at $100 \%$ (overcast-sky) with the other cloud properties (optical depth, heights, etc.) unchanged with respect to the observations. The second experiment is the most realistic, but the other two set the bounds of sea-ice forcing in the case of future cloud amount increases or decreases due to climate change.

The modelled sea-ice forcing follows a seasonal cycle with maxima in June (largest solar fluxes) and zero values in Arctic winter. There is a general decrease after 1999, in expected synchronisation with the sea-ice extent. The forcing magnitude is largest for the clear-sky case, when downwelling and reflected solar fluxes are maximised due to the lack of clouds, while it is reduced for the all-sky case and becomes minimum for the overcast-sky case. The long-term annually averaged forcings are presented in Table 2, both for the whole planet and for the Arctic Ocean.

We used the same methodology to calculate the effect of the forecasted September total sea-ice meltdown. Even if in all other months sea ice keeps its climatological extent, if we remove it for September, the annual absorbed solar flux increases by $0.32 \mathrm{Wm}^{-2}$, if we average spatially over the Arctic. The local effect of a September ice-free Arctic Ocean is eight times smaller than the enhanced greenhouse effect $\left(2.5 \mathrm{Wm}^{-2}\right)$.

The spatial distribution of the net solar flux and its trends were presented. In agreement with Perovich et al. (2007), the largest statistically significant positive trends (consistent with decreasing sea-ice extent) were at North Chukchi and Kara Seas, Baffin and Hudson Bays, and Davis Strait. However, we found considerably smaller trends in this study.

In a sensitivity analysis of the sea-ice forcing with respect to sea-ice extent and cloud cover, the interplay of the three quantities became evident. However, we did not identify any strong non-linear behaviour. When sea-ice extent and cloud cover were modified, the effect on the forcing was not very different from the sum of the individual effects.

Acknowledgements. The ISCCP D2 data were obtained from the International Satellite Cloud Climatology Project web site http://isccp.giss.nasa.gov maintained by the ISCCP research group at the NASA Goddard Institute for Space Studies, New York, NY. The GADS aerosol data were obtained from the Meteorological Institute of the University of Munich. NCEP/NCAR Reanalysis Derived data provided by the NOAA/OAR/ESRL PSD, Boulder, Colorado, USA, from their Web site at http://www.cdc.noaa.gov/. This research was co-funded by a Research Programme in Environmental Sciences by the John S. Latsis Public Benefit Foundation.

Edited by: N. Mihalopoulos

\section{References}

Aizen, V. B., Aizen, E. M., Melack, J. M., and Dozier, J.: Climate and hydrological changes in the Tien Shan, central Asia, J. Climate, 10, 218-229, 1997.

Cavalieri, D. J., Gloersen, P., and Campbell, W. J.: Determination of sea ice parameters with the NIMBUS-7 SMRR, J. Geophys. Res., 89, 5355-5369, 1984.

Comiso, J. C., Parkinson, C. L., Gersten, R., and Stock, L.: Accelerated decline in the Arctic Sea ice cover, Geophys. Res. Lett., 35, L01703, doi:10.1029/2007GL031972, 2008.

Forster, P., Ramaswamy, V., Artaxo, P., Berntsen, T., Betts, R., Fahey, D., Haywood, J., Lean, J., Lowe, D., Myhre, G., Nganga, J., Prinn, R., Raga, G., Schulz, M., and Dorland, R. V.: Changes in Atmospheric Constituents and in Radiative Forcing. In: Climate Change 2007: The Physical Science Basis. Contribution of Working Group I to the Fourth Assessment Report of the Intergovernmental Panel on Climate Change, Cambridge University Press, Cambridge, United Kingdom and New York, NY, USA, 2007.

Gorodetskaya, I. V., Tremblay, L.-B., Liepert, B., Cane, M. A., and Cullather, R. I.: The influence of cloud and surface properties on the Arctic Ocean shortwave radiation budget in coupled models, J. Climate, 21, 866-882, 2008.

Groisman, P., Karl, T. R., and Knight, R. W.: Observed impact of snow cover on the heat balance and the rise of continental spring temperatures, Science, 263, 198-200, 1994.

Hartmann, D. L.: Global Physical Climatology, Academic Press, London, UK, p. 23, 1994. 
Hatzianastassiou, N., Cleridou, N., and Vardavas, I.: Polar cloud climatologies from ISCCP C2 and D2 datasets, J. Climate, 14, 3851-3862, 2001.

Hatzianastassiou, N., Katsoulis, B., and Vardavas, I.: Global distribution of aerosol direct radiative forcing in the ultraviolet and visible arising under clear skies, Tellus, 56B, 51-71, 2004a.

Hatzianastassiou, N., Matsoukas, C., Hatzidimitriou, D., Pavlakis, C., Drakakis, M., and Vardavas, I.: Ten-year radiation budget of the Earth: 1984-1993, Int. J. Climatol., 24, 1785-1802, 2004b.

Hatzianastassiou, N., Matsoukas, C., Fotiadi, A., Stackhouse, P. W., Koepke, P., Pavlakis, K. G., and Vardavas, I.: Modelling the direct effect of aerosols in the solar near-infrared on a planetary scale, Atmos. Chem. Phys., 7, 3211-3229, 2007a, http://www.atmos-chem-phys.net/7/3211/2007/.

Hatzianastassiou, N., Matsoukas, C., Drakakis, E., Stackhouse, P. W., Koepke, P., Fotiadi, A., Pavlakis, K. G., and Vardavas, I.: The direct effect of aerosols on solar radiation based on satellite observations, reanalysis datasets, and spectral aerosol optical properties from Global Aerosol Data Set (GADS), Atmos. Chem. Phys., 7, 2585-2599, 2007b, http://www.atmos-chem-phys.net/7/2585/2007/.

Joseph, J. H., Wiscombe, W. J., and Weinmann, J. A.: The DeltaEddington approximation of radiative flux transfer, J. Atmos. Sci., 33, 2452-2459, 1976.

Kistler, R., Kalnay, E., Collins, W., Saha, S., White, G., Woolen, J., Chelliah, M., Ebisuzaki, W., Kanamitsu, M., Kousky, V., van den Dool, H., Jenne, R., and Fiorino, M.: The NCEP-NCAR 50-year reanalysis: Monthly means CD-ROM and documentation, Bull. Amer. Meteorol. Soc., 82, 247-268, 2001.

Köpke, P., Hess, M., Schult, I., and Shettle, E. P.: Global aerosol data set. Rep. No. 234, Tech. rep., Max Planck Institut für Meteorologie, 1997.

Kuang, Z. and Yung, Y. L.: Observed albedo decrease related to the spring snow retreat, Geophys. Res. Lett., 27, (9), 1299-1302, 2000.

Lemke, P., Ren, J., Alley, R., Allison, I., Carrasco, J., Flato, G., Fujii, Y., Kaser, G., Mote, P., Thomas, R., and Zhang, T.: Observations: Changes in Snow, Ice and Frozen Ground. In: Climate Change 2007: The Physical Science Basis. Contribution of Working Group I to the Fourth Assessment Report of the Intergovernmental Panel on Climate Change, Cambridge University Press, Cambridge, UK and New York, NY, USA, 2007.

Liu, J., Curry, J. A., Rossow, W. B., Key, J. R., and Wang, X.: Comparison of surface radiative flux data sets over the Arctic Ocean, J. Geophys. Res., 110, C02015, doi:10.1029/2004JC002381, 2005.
NSIDC: Arctic sea ice down to second-lowest extent; Likely recordlow volume, http://www.nsidc.org/news/press/20081002_seaice_ pressrelease.html, 2008.

Perovich, D. K., Light, B., Eicken, H., Jones, K. F., Runciman, K., and Nghiem, S. V.: Increasing solar heating of the Arctic Ocean and adjacent seas, 1979-2005: Attribution and role in the icealbedo feedback, Geophys. Res. Lett., 34, L19505, doi:10.1029/ 2007GL031480, 2007.

Rossow, W. B. and Schiffer, R. A.: Advances in understanding clouds from ISCCP, Bull. Amer. Meteorol. Soc., 80, 2261-2287, 1999.

Serreze, M. C., Key, J. R., Box, J. E., Maslanik, J. A., and Steffen, K.: A New Monthly Climatology of Global Radiation for the Arctic and Comparisons with NCEP-NCAR Reanalysis and ISCCP-C2 Fields, J. Climate, 11, 121-136, 1998.

Serreze, M. C., Holland, M. M., and Stroeve, J.: Perspectives on the Arctic's Shrinking Sea-Ice Cover, Science, 315, 1533-1536, doi:10.1126/science.1139426, 2007.

Stone, R. S., Dutton, E. G., Harris, J. M., and Longenecker, D.: Earlier spring snowmelt in northern Alaska as an indicator of climate change, J. Geophys. Res., 107, 4089, doi:10.1029/ 2000JD000286, 2002.

Stroeve, J., Serreze, M. C., Fetterer, F., Arbetter, T., Meier, W., Maslanik, J., and Knowles, K.: Tracking the Arctics shrinking ice cover: Another extreme September minimum in 2004, Geophys. Res. Lett., 32, L04501, doi:10.1029/2004GL021810, 2005.

Stroeve, J., Serreze, M., Drobot, S., Gearheard, S., Holland, M., Maslanik, J., Meier, W., and Scambos, T.: Arctic sea ice extent plummets in 2007, EOS, 89, 13-14, 2008.

Thekaekara, M. P. and Drummond, A. J.: Standard values for the solar constant and its spectral components, Nat. Phys. Sci., 229, 6-9, 1971 .

Vardavas, I. and Taylor, F.: Radiation and Climate, Oxford University Press, New York, NY, USA, p. 9, 2007.

Vardavas, I. M. and Carver, J. H.: Solar and terrestrial parameterizations for radiative-convective models, Planet. Space Sci., 32, 1307-1325, 1984.

Wang, X. and Key, J. R.: Arctic surface, cloud, and radiation properties based on AVHRR Polar Pathfinder dataset. Part I: Spatial and temporal characteristics, J. Climate, 18, 2558-2574, $2005 \mathrm{a}$.

Wang, X. and Key, J. R.: Arctic surface, cloud, and radiation properties based on AVHRR Polar Pathfinder dataset. Part II: Recent trends, J. Climate, 18, 2575-2593, 2005b.

Willson, R. C.: Total solar irradiance trend during solar cycles 21 and 22, Science, 277, 1963-1965, 1997. 